\title{
The Metabolic Mechanism of Cerebral Blood Flow Autoregulation in Dogs
}

\author{
Masatoshi Fujishima, M.D.
}

\begin{abstract}
SUMmaRy
The effects of lowered perfusion pressure on the cerebral circulation, and on the lactate and acid-base parameter in cerebrospinal fluid (CSF) were studied in the light-anesthetized dogs. The cerebral perfusion pressure was lowered by bleeding the animal at the controlled arterial $\mathrm{PCO}_{2}$. There was a progressive increase in cisternal CSF lactate with consequent decrease in CSF $\mathrm{pH}$ and bicarbonate when perfusion pressure was reduced even though cerebral blood flow was unchanged. It is concluded that cerebral autoregulation in response to reduced perfusion pressure appears to be a function of tissue lactic acidosis, signifying tissue hypoxia due to the lowering of local cortical blood flow.
\end{abstract}

\section{Additional Indexing Words :}

CSF lactic acidosis Anaerobic glycolysis Constant CBF Variable Cortical flow

\begin{abstract}
$\mathrm{A}$ UTOREGULATION is the capacity of the vessels to constrict in response to increased perfusion pressure and dilate in response to decreased perfusion pressure. This characteristic of cerebral vessels is important in control of cerebral circulation and it is lost in hypercapnia, ${ }^{1), 2)}$ ischemia, ${ }^{31,4)}$ prolonged hypoxia ${ }^{5},{ }^{6}$ or brain injury. ${ }^{71}$ There are several hypotheses, each of which brings something to the understanding of this intrinsic vascular process, but none of which is sufficient to elucidate the mechanism of cerebral autoregulation. These hypotheses include the myogenic or "vascular reflex " theory of Bayliss, ${ }^{8}$ ) the homeostatic mechanism of carbon dioxide and oxygen,9" and recently espoused concept that autoregulation to diminished perfusion pressure induced by elevated intracranial pressure is the function of tissue hypoxia of the brain. ${ }^{10}$ ) The role of the autonomic nervous system, ${ }^{11)}$ and brain stem ${ }^{12)}$ in this process is not yet settled, but the existing evidence would probably not support a single hypothesis to the exclusion of all other influences.

The present study was undertaken to test the hypothesis that autoregulation to decreased perfusion pressure by bleeding would be a function of lactic acidosis in the cerebrospinal fluid and that this hypoxic reaction of the brain
\end{abstract}

From the Second Department of Internal Medicine, Kyushu University School of Medicine, Fukuoka.

Received for publication January 29, 1971. 
tissue to diminished perfusion pressure would be due to the insufficient blood supply to the local cerebral regions, even within the autoregulatory range of perfusion pressure, in which total cerebral blood flow (CBF) remains unchanged.

\section{METHODS}

Nine mongrel dogs weighing 15 to $22 \mathrm{Kg}$. were used for this experiment. The animals were anesthetized with $25 \mathrm{mg} . \mathrm{Kg}$. of intravenous sodium pentobarbital and intubated. Both femoral arteries were cannulated, one for blood pressure recording with a pressure transducer, and the other for blood withdrawal. A femoral vein was cannulated to administer fluid and restore the blood. The animals were paralyzed with $3 \mathrm{mg}$. $/ \mathrm{Kg}$. of gallamine $\mathrm{HCl}$, and respired artificially. Endtidal $\mathrm{CO}_{2}$ was monitored by Beckman infrared gas analyzer.

$\mathrm{CBF}$ was continuously measured by the venous out-flow technique using a magnetic flow meter. ${ }^{13}$ ) Cortical blood flow was measured by a compensated heated thermistor flow probe placed gently in the left parietal cortex through a $2 \mathrm{~mm}$. burr hole with wide deflection of both temporal muscles from the skull. A 18 gauge needle was inserted by a percutaneous midline puncture into the cisterna magna for obtaining CSF samples.

During experiments, the following functions were recorded on a 8 channel recorder; Electrocardiogram, left front-occipital electroencephalogram, CBF, cortical blood flow, arterial and cerebral venous pressure, and end-tidal $\mathrm{CO}_{2}$ concentration. Direct samples of arterial and cerebral venous bloods, and CSF were analyzed in the following manner; oxygen and carbon dioxide tension $\left(\mathrm{PO}_{2}, \mathrm{PCO}_{2}\right)$, and $\mathrm{pH}$ by an IL meter, $\mathrm{O}_{2}$ and $\mathrm{CO}_{2}$ contents in blood with the Van Slyke manometric apparatus, and lactate concentration in arterial blood and CSF by the enzymatic method. ${ }^{14)}$

After completing the operation, a resting control period of $30 \mathrm{~min}$. was allowed before the experiment. Following the determination of each parameter, the animals were slowly bled from the arterial cannula into the reservoir flask when desired arterial pressure was obtained and maintained for at least $15 \mathrm{~min}$. at the same level. Arterial $\mathrm{PCO}_{2}$ was kept constant by controlling the respirator. The blood and CSF samples were taken at the end of each period of the different pressure levels.

At the termination of experiments, the brain was removed and the location of the flow probe was confirmed.

\section{Results}

(1) Cerebral blood flow (CBF), cerebral vascular resistance (CVR), and cerebral metabolic rate of oxygen $\left(\mathrm{CMRO}_{2}\right)$ during lowered perfusion pressure: Fig. 1 depicts the means of the percentage changes from the control values of $\mathrm{CBF}, \mathrm{CVR}$, and $\mathrm{CMRO}_{2}$ when mean arterial pressure (MAP) was stepwise-reduced by bleeding the animal. $\mathrm{CBF}$ remained unchanged at MAP 


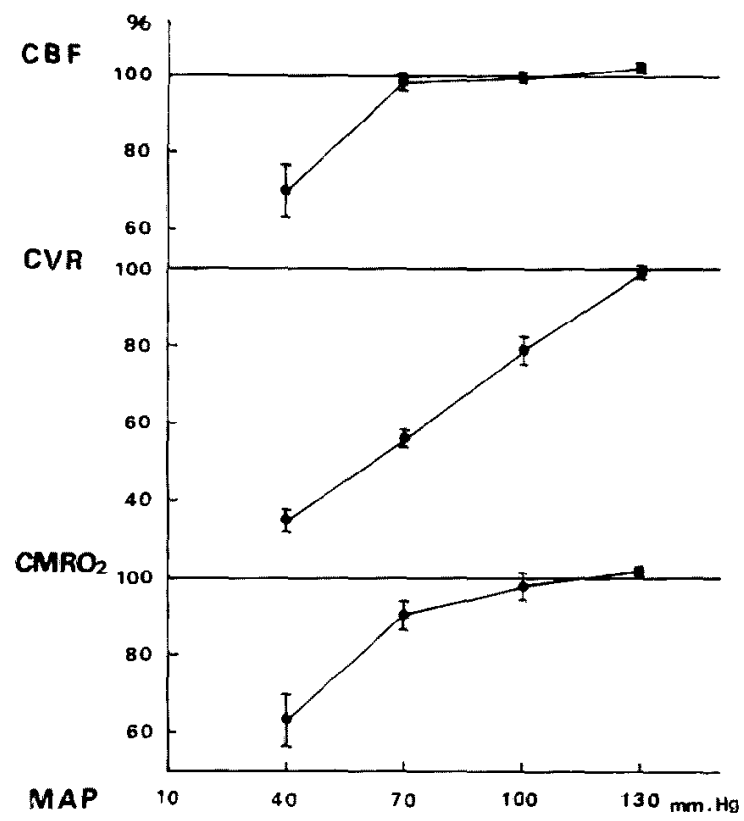

Fig. 1. The means of the percent changes from the control values of cerebral blood flow (CBF), cerebral vascular resistance (CVR), and cerebral metabolic rate of oxygen $\left(\mathrm{CMRO}_{2}\right)$ when mean arterial blood pressure was reduced by blceding animals.

ranging from 130 to $70 \mathrm{~mm} . \mathrm{Hg}$, with resultant decrease in CVR. Below 70 $\mathrm{mm} . \mathrm{Hg}$ of MAP, however, CBF decreased following the decreased MAP, indicating that cerebral autoregulation was abolished.

The mean value of $\mathrm{CMRO}_{2}$ was not changed until MAP was lowered to $70 \mathrm{~mm} . \mathrm{Hg}$, although in 2 animals $\mathrm{CMRO}_{2}$ began to decrease even above this pressure level.

(2) Cortical blood flow during lowered perfusion pressure: The qualitative changes of local cortical blood flow in the parietal cortex is demonstrated in Fig. 2. The reactivity of the local cortical vessels to lowered perfusion pressure was a non-uniform phenomenon; decrease in cortical flow was observed in some animals or slight increase in others, although CBF remained constant until MAP was reduced to $70 \mathrm{~mm}$.Hg. Below $50 \mathrm{~mm} . \mathrm{Hg}$, however, cortical blood flow as well as CBF decreased in respose to lowering perfusion pressure in every instance.

(3) Lactate concentration and acid-base parameter in cisternal fluid during lowered perfusion pressure: Fig. 3 depicts that a small but progressive increase in CSF lactate occurred in response to a relatively slight fall of MAP. Below $70 \mathrm{~mm} . \mathrm{Hg}$ of MAP, CSF lactate was greatly increased. Both the CSF $\mathrm{pH}$ and bicarbonate concentration were consistently decreased with 


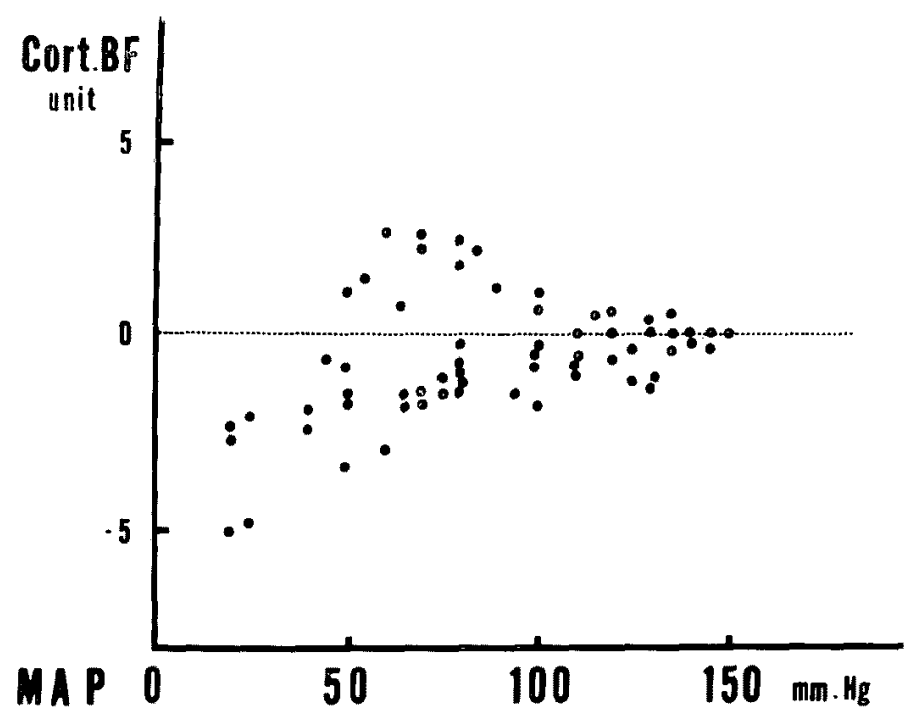

Fig. 2. The qualitative changes of cortical blood flow in the parietal region of brain during lowered arterial pressure. The behavior of cortical flow in response to lowered MAP was non-uniform even within the CBF autoregulatory range of $\mathrm{MAP}$.

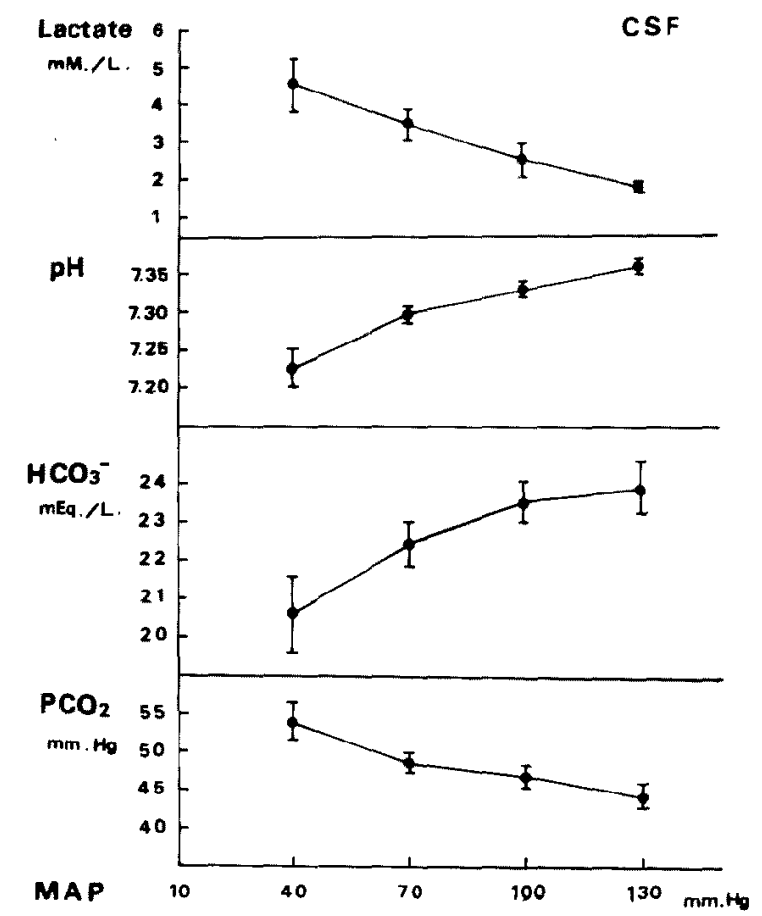

Fig. 3. The mean values of the changes of lactate, $\mathrm{pH}$, bicarbonate concentration and $\mathrm{PCO}_{2}$ in $\mathrm{CSF}$ in response to lowered arterial pressure. A progressive increase in CSF lactate with simultaneous decrease in CSF pH and bicarbonate occurred when MAP was reduced to $70 \mathrm{~mm} . \mathrm{Hg}$, although CBF remained unchanged. 
insignificant increase in $\mathrm{CSF} \mathrm{PCO}_{2}$, when MAP was lowered to $70 \mathrm{~mm}$. Hg. Arterial $\mathrm{PCO}_{2}$ remained constant by adjusting respiration. Increase in arterial lactate in response to lowered MAP was progressive and much greater than that in CSF lactate as shown in Table I.

Table I. The Mean Values of Cerebrospinal Fluid and Arterial Lactate and Acid-Base Parameter During Stepwise Reduction of Mean Arterial Blood Pressure in 9 Light-Anesthetized Dogs

\begin{tabular}{lc|c|c|c}
\hline MAP (mm. Hg) & $140-120$ & $110-90$ & $80-60$ & $50-30$ \\
\hline $\mathrm{CSF}$ & & & & \\
Lactate (mM./L.) & $1.84 \pm 0.12$ & $2.48 \pm 0.45$ & $3.42 \pm 0.44$ & $4.51 \pm 0.72$ \\
$\mathrm{pH}(\mathrm{Unit})$ & $7.358 \pm 0.010$ & $7.328 \pm 0.011$ & $7.295 \pm 0.010$ & $7.225 \pm 0.025$ \\
$\mathrm{HCO}_{3}^{-}(\mathrm{mEq} / \mathrm{L})$. & $23.9 \pm 0.7$ & $23.5 \pm 0.6$ & $22.4 \pm 0.6$ & $20.6 \pm 1.0$ \\
$\mathrm{PCO}_{2}(\mathrm{~mm} . \mathrm{Hg})$ & $44.2 \pm 1.6$ & $46.8 \pm 1.5$ & $48.6 \pm 1.2$ & $53.9 \pm 2.4$ \\
Arterial & & & & \\
Lactate & $0.90 \pm 0.17$ & $2.73 \pm 0.46$ & $5.24 \pm 0.73$ & $9.07 \pm 1.33$ \\
PCO & $37.8 \pm 1.3$ & $37.5 \pm 1.1$ & $39.6 \pm 1.6$ & $34.3 \pm 3.1$ \\
* values are mean $\pm \mathrm{SEM}$ & & &
\end{tabular}

\section{Discussion}

Many observations have suggested that the $\mathrm{pH}$ in CSF as the representative of the extracellular fluid in the brain is one of the main factors regulating CBF. ${ }^{151,16)}$ Fencl et al. ${ }^{17}$ demonstrated that CBF was higher in CSF acidosis and lower in alkalosis as compared with normal CSF pH, and they concluded that $\mathrm{CBF}$ is regulated with $\mathrm{CSF}$ pH, not with $\mathrm{PCO}_{2}$ in chronic metabolic acidbase changes.

The present experiments show that a consistent and progressive increase in the lactate concentration of the cisternal CSF occurred with consequent decrease in the CSF $\mathrm{pH}$ and bicarbonate concentration when cerebral perfusion pressure was reduced by bleeding the animal, although CBF remained unchanged. The increased concentration of body fluid lactate is considered to be due to 2 mechanisms; first is the increased breakdown of glucose, producing pyruvic acid in proportion to the increase in lactic acid. Such a proportional increase in both metabolites may occur after glucose infusion, epinephrine injection or systemic alkalosis. ${ }^{18)}$ Second is the accelerated anaerobic glycolysis producing excess lactic acid with less increase in pyruvic acid, resulting in an increase in the lactate-pyruvate ratio. Such a disproportional increase in lactic acid may occur in hypoxia, ${ }^{191}$ ischemia $^{201}$ or hypocapnia. ${ }^{21)}$ CSF lactic acidosis with a constant $\mathrm{PCO}_{2}$ in this study may strongly suggest that 
the tissue glucose metabolism is changed in the direction of anaerobiosis. Then, a question could be raised why the brain tissue becomes hypoxic with a constant CBF. Cortical blood flow, however, varied in response to lowered perfusion pressure even within an autoregulatory range, suggesting that a small reduction of perfusion pressure might cause an insufficient blood supply to the certain regions of the brain, such as those situated between the distribution field of major arteries, so-called "water-shed area". The similar phenomenon as non-uniform reactions of the cortical vessels was observed in response to the inhalation of $6 \%$ oxygen in nitrogen gas mixture or to the drug-induced hypertension in animals. ${ }^{22)}$ Baldy-Moulinier and Frerebeau ${ }^{23)}$ demonstrated that the elevation of intracranial fluid pressure was followed by a gradual and progressive decrease in regional cortical blood flow despite no change in global cerebral blood flow. These observations suggest that lowered perfusion pressure might lead to the circulatory insufficiency in some areas of the brain, where the anaerobic glycolysis might be accelerated.

Alexander et al. ${ }^{24}$ reported that CSF lactate concentration was unaffected by the raised arterial lactate of dogs from 2 to $13 \mathrm{mEq} / \mathrm{L}$. by intravenous infusion. Klein and Olsen ${ }^{25}$ have also observed the brain lactate levels are not altered by acute changes in the levels of circulating blood lactate. In the present study, however, showing that increase in arterial lactate was much greater and faster than that in CSF lactate when MAP was lowered, it will be difficult to exclude the possibility of the diffusion of lactate from circulating blood to CSF space.

Although $\mathrm{Kjällquist} \mathrm{et} \mathrm{al.}{ }^{26)}$ demonstrated a linear relation between increase in CSF lactate and decrease in CSF bicarbonate after reduction of perfusion pressure by raising intracranial pressure, the present results have shown that decrease in CSF bicarbonate was much greater than increase in CSF lactate, suggesting that some additional acids other than lactic acid could be produced in response to hypotensive stimuli, or CSF bicarbonate could be transported actively or passively from CSF space to circulating blood. The former possibility is less likely, because CSF acidification by the product of metabolism other than lactic acid, such as pyruvic acid, at the constant $\mathrm{PCO}_{2}$ is much smaller than that by lactic acid. The latter appears to be more likely that much greater increase in arterial lactate than in CSF lactate could cause the wider gradient of bicarbonate concentrations and the greater difference of electrochemical potential between CSF and plasma. ${ }^{27}$

Although the present results strongly suggest that cerebral autoregulation to decreased perfusion pressure appears to be a function of CSF lactic acidosis, they do not allow any conclusion regarding the transportation of lactate and bicarbonate between CSF space and blood, until the further results are obtained. 


\section{References}

1. Harper, A. M.: J. Ncurol. Neurosurg. Psychiat. 29: 398, 1966.

2. Häggendal, E. and Johansson, B.: Acta Physiol. Scand. 66(Suppl. 258): 27, 1965.

3. Waltz, A. G.: Neurology 18:613, 1968.

4. Fiesci, C., Agnoli, A., Battistini, N., Bozzao, L., and Prencipe, M.: Neurology 18: 1166, 1968.

5. Kogure, K., Scheinberg, P., Fujishima, M., Reinmuth, O. M., and Busto, R.: Am. J. Physiol. 219: $1393,1970$.

6. Häggendal, E.: Scand. J. Lab. Clin. Invest. Suppl. 102: V: D, 1968.

7. Reivich, M., Marshall, W. J. S., and Kassel, N.: in Cerebral Blood Flow, ed. by Brock, M. et al., Springer-Verlag, Berlin, p. 205, 1969.

8. Bayliss, W. M.: J. Physiol. (London) 28: 220, 1902.

9. Sokoloff, L. and Kety, S. S.: Physiol. Rev. 40(Suppl. 4): 38, 1960.

10. Zwetnow, N. N.: Acta Physiol. Scand. Suppl. 339: 1, 1970.

11. James, I. M., Millar, R. A., and Purves, M. J.: Circulat. Res. 25: 77, 1969.

12. Molnár, L. and Szanto, J.: Quart. J. Exp. Physiol, 49: 184, 1964.

13. Rapela, C. E. and Green, H. D.: Circulat. Res. 14 15(Suppl. I): 205, 1964.

14. Hess, B.: Biochem. Z. 328: 110, 1956.

15. Betz, E. and Heuser, D.: J. Appl. Physiol. 23: 726, 1967.

16. Skinhøj, E.: Acta Neurol. Scand. 42: 604, 1966.

17. Fencl, V., Vale, J. R., and Broch, J. A.: J. Appl. Phsyiol. 27: 67, 1969.

18. Huckabee, W. E.: J. Clin. Invest. 37: 244, 1958.

19. Kaasik, A. E., Nilsson, L., and Siesjö, B. K.: Acta Physiol. Scand. 78: 433, 1970.

20. Kaasik, A. E., Nilsson, L., and Siesjö, B. K.: Ibid. 78: 448, 1970.

21. Granholm, L. and Siesjö, B. K.: Acta Physiol, Scand. 75: 257, 1969.

22. Fujishima, M., Scheinberg, P., and Busto, R.: in Preparation.

23. Baldy-Moulinier, M. and Frerebeau, Ph.: Scand. J. Lab. Clin. Invest. Suppl. 102: V: G, 1968.

24. Alexander, S. C., Workman, R. D., and Lambertsen, C. J.: Am. J. Physiol. 202: 1049, 1962.

25. Klein, J. R. and Olsen, N. S.: J. Biol. Chem. 167: 1, 1947.

26. Kjällquist, A., Siesjö, B. K., and Zwetnow, N.: Acta Physiol. Scand. 75: 345, 1969.

27. Kjällquist, A. and Siesjö, B. K.: Scand. J. Lab. Clin. Invest. Suppl. 102: 1 : G, 1968. 